\title{
DRYING CHARACTERISTICS INVESTIGATION OF BLACK MULBERRY DRIED VIA INFRARED METHOD
}

\author{
I. Doymaz ${ }^{1}$ A. S. Kipcak ${ }^{*}$
}

\begin{abstract}
In this study, the drying characteristics of black mulberry were studied by using the drying method of infrared. Infrared power levels were selected between 50 and $104 \mathrm{~W}$. The obtained drying data were applied to several drying models (Aghbashlo et al., Page, Parabolic, Wang and Singh and Weibull), which gave the high the coefficient of determination $\left(\mathrm{R}^{2}\right)$ values. The best modelling method were selected based on the highest $R^{2}$, and the lowest reduced chi-square $\left(\chi^{2}\right)$, and root mean square errors. Also, the effective moisture diffusivity was calculated using the Fick's second law's spherical coordinate approximation. The activation energies were calculated from the values of the effective moisture diffusivity with respect to mass over power levels. From the results it was seen that the Parabolic type of drying model best fits the data obtained with the $\mathrm{R}^{2}$ values between $0.997849(104 \mathrm{~W})-0.999664(62 \mathrm{~W})$. The effective moisture values were obtained between $1.14 \times 10^{-9}-3.08 \times 10^{-}$ ${ }^{9} \mathrm{~m}^{2} / \mathrm{s}$ and increased as the infrared power level increased. The activation energy was calculated as $2.015 \mathrm{~kW} / \mathrm{kg}$.
\end{abstract}

Keywords: Drying, Black Mulberry, Infrared, Modelling, Effective Moisture Diffusivity, Activation Energy

\section{INTRODUCTION}

Mulberry has been cultivated in the Northern hemisphere for centuries on account of its wide use for many purposes [1]. Three mulberry trees are extensively grown (e.g. southern Europe, India) for their leaves as foods for silkworms. Their fruits can be eaten raw or dried. There are three kinds of mulberry: Red mulberry (Morusrubra L.), white mulberry (Morusalba L.) and black mulberry (Morusnigra L.). White mulberry originated in Western Asia, red mulberry in North and South America, and black mulberry is from Southern Russia. They have a high level of moisture content at harvest [2]. The mulberry leaf is a promising dietary source of antioxidants such as quercetin due to its relatively high content of that compound [3]. In Turkey among fruits, berry fruits including grapes share $25 \%$ of total fruit production of the country. The most important berry fruits in terms of amount of production in Turkey after grape are strawberry (average 200000 tons production annually) and followed by mulberry (70000 tons), raspberry and blackberry (30000 tons) and blueberry (5000 tons) [4].

Due to the microbiological activity, food products can easily spoil and decay. This problem can be solved by decreasing the moisture content of the food products. Drying is a traditional method that is used in the food industry. The drying process is intended to remove water from foodstuff to prevent microbial spoilage and chemical alterations, thus prolonging shelf-life while realizing space and weight savings. Infrared drying has gained popularity as an alternative drying method for agricultural products. Several methods can be found in the literature and among them the infrared method has many advantages such as high energy efficiency and short drying times. This advantages are is due to quick absorption of energy by water molecules, which causes rapid evaporation of water and results in high drying rates of food and, thus, leads to a decrease of drying time and, therefore, to lower energy consumption and better quality of the dried food $[5,6]$. Infrared drying is used in the drying of several agricultural products including apple slices [7, 8], peach [9], grape by-products [10], and seedless grape [11]. However, no study on infrared drying of black mulberry has been reported in literature. The main objectives of this study were to investigate the effect of infrared power on drying characteristics, fit the experimental data to five drying models, and compute effective moisture diffusivity and activation energy black mulberry.

\section{MATERIALS AND METHODS Raw material}

Good quality fresh black mulberry (Morusnigra L.) was purchased from a local market in Istanbul, Turkey. The initial moisture content of mulberry samples was determined by using oven at $105^{\circ} \mathrm{C}$ for $24 \mathrm{~h}$. 
Triplicate samples were used for the determination of moisture content and the average values were reported as $90.73 \%$, w.b. (9.787 kg water/kg dry matter, d.b.).

\section{Experimental procedure}

Drying experiments were carried out in a moisture analyzer with one $250 \mathrm{~W}$ halogen lamp (Snijders Moisture Balance, Snijdersb.v., Tilburg, Holland), which is given in Figure 1.

The experiments were carried out at five infrared powers, that is 50,62, 74, 88 and $104 \mathrm{~W}$ infrared powers. The infrared power was set in control unit of equipment. Approximately $50 \mathrm{~g}$ of sample, the radius of a mulberry was about $1.90 \mathrm{~cm}$, was put into the dryer after weighting. The weighing interval of drying process was 15 min during the drying process. A digital balance (Mettler-Toledo AG, Grefensee, Switzerland, model BB3000) with $0.1 \mathrm{~g}$ accuracy was employed to record the sample weight during the experiment. The drying process was finished when the moisture content reached to value of $0.24 \pm 0.01 \mathrm{~kg}$ water $/ \mathrm{kg}$ dry matter (d.b.). The dried product was cooled at room temperature about $10 \mathrm{~min}$ and then packed in low-density polyethylene bags that were heat-sealed. The experimental tests were replicated three times at each infrared power and weight loss averages are reported.

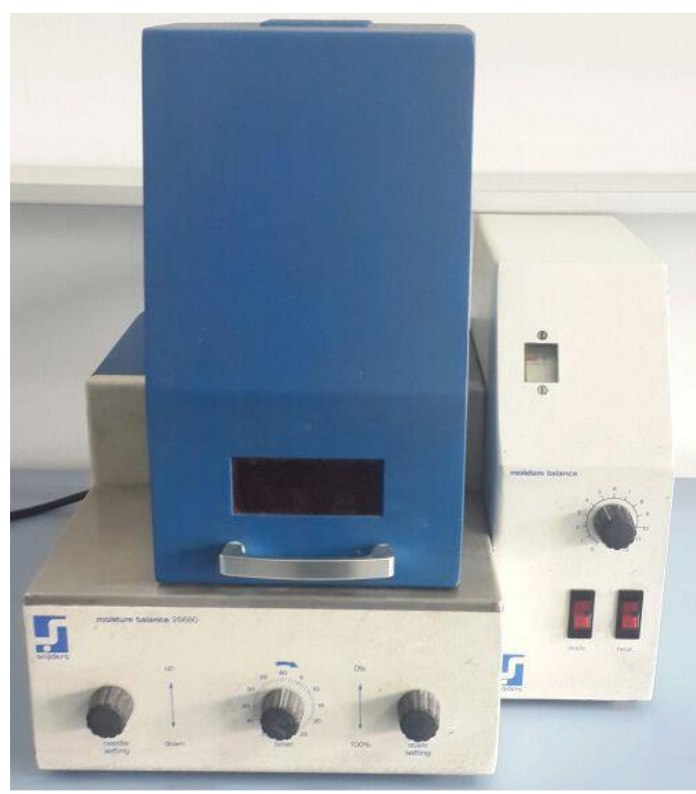

Figure 1. Moisture analyzer equipment

\section{Mathematical modelling}

The experimental drying data obtained at different infrared powers were fitted using five drying models (Table 1). The moisture content $(M)$, moisture ratio $(M R)$ and drying rate $(D R)$ of samples were calculated using the following equations:

$$
\begin{gathered}
M=\frac{W-W_{d}}{W_{d}} \\
M R=\frac{M_{t}-M_{e}}{M_{o}-M_{e}} \\
D R=\frac{M_{t}-M_{t+\Delta t}}{d t}
\end{gathered}
$$

where $M$ is the moisture content ( $\mathrm{kg}$ water $/ \mathrm{kg}$ dry matter), $W$ is weight of sample $(\mathrm{kg}), W_{d}$ is dry matter content of sample (kg), and t is time ( $\min ) . M_{0}, M_{e}, M_{t}$ and $M_{t+d t}$ are initial moisture content, equilibrium moisture content, moisture content at $\mathrm{t}$ and $t+d t$ ( $\mathrm{kg}$ water $/ \mathrm{kg}$ dry matter), respectively. As the $M_{e}$ is very small compared to $M_{0}$ and $M_{t}$ values, the $M_{e}$ can be neglected and $M R$ can be expressed as $M_{t} / M_{0}[12]$. 
Journal of Thermal Engineering, Research Article, Vol. 5, No. 2, Special Issue 9, pp. 13-21, February, 2019

Table 1. Models used in fitting the experimental data

\begin{tabular}{|c|c|c|}
\hline Model name & Equation & Reference \\
\hline Aghbashlo et al. & $M R=\exp \left(-\frac{k_{1} t}{1+k_{2} t}\right)$ & {$[13]$} \\
\hline Page & $M R=\exp \left(-k t^{n}\right)$ & {$[14]$} \\
\hline Parabolic & $M R=a+b \times t+c \times t^{2}$ & {$[6]$} \\
\hline Wang and Singh & $M R=1+a \times t+b \times t^{2}$ & {$[15]$} \\
\hline Weibull & $M R=\exp \left(-\left(\frac{t}{b}\right)^{a}\right)$ & {$[16]$} \\
\hline
\end{tabular}

\section{Data analysis}

Data were analyzed using Statistica 8.0.550 (StatSoft Inc., USA) software package. The parameters of models were estimated using a non-linear regression procedure based on the Levenberg-Marquardt algorithm. The fitting quality of the experimental data to all models was evaluated using the coefficient of determination $\left(R^{2}\right)$, reduced chi-square $\left(\chi^{2}\right)$ and root mean square error $(R M S E)$. The $\chi^{2}$ and RMSE were calculated from the following formulas:

$$
\begin{gathered}
\chi^{2}=\frac{\sum_{i=1}^{N}\left(M R_{e x p, i}-M R_{p r e, i}\right)^{2}}{N-z} \\
R M S E=\left[\frac{1}{N} \sum_{i=1}^{N}\left(M R_{p r e, i}-M R_{\text {exp }, i}\right)^{2}\right]^{1 / 2}
\end{gathered}
$$

where $M R_{\text {exp }, i}$ and $M R_{p r e, i}$ are experimental and predicted dimensionless moisture ratios, respectively; $N$ is number of observations; $z$ is number of constants. The higher $R^{2}$ values and the lower $\chi^{2}$ and $R M S E$ values provide a better quality of fit [17-19].

\section{Calculation of effective moisture diffusivity}

Diffusion is a complex process that takes place during the drying of the food. Drying characteristics of biological products can be described by the Fick's diffusion equation at the falling-rate period [20]. The okra slices can be assumed as in the form of spherical and the Fick's second law of diffusion for spherical object is defined as follows:

$$
\frac{\partial M}{\partial t}=D_{e f f}\left[\frac{\partial^{2} M}{\partial \chi^{2}}\right]
$$

where $M$ is the moisture content and $D_{\text {eff }}$ is the effective moisture diffusivity $\left(\mathrm{m}^{2} / \mathrm{s}\right)$. The assumptions involved in the diffusion analysis are: uniform initial moisture content, internal moisture movement as the main resistance, negligible external resistance to heat and mass transfer, a constant effective diffusion coefficient. Crank (1975) gave the analytical solution to Eq. 6 for object with spherical geometry, which is given in Eq. (7) [21]: 


$$
M R=\frac{6}{\pi^{2}} \sum_{n=1}^{\infty} \frac{1}{n^{2}} \exp \left[-\frac{n^{2} \pi^{2} D_{e f f} t}{r^{2}}\right]
$$

where $t$ is the drying time (s) and $r$ is the radius of the spherical object $(\mathrm{m})$. To be able to determine the effective moisture diffusivity, Eq. (7) may be simplified to a linear logarithmic form:

$$
\ln (M R)=\ln \left(\frac{6}{\pi^{2}}\right)\left(\frac{\pi^{2} D_{e f f} t}{r^{2}}\right)
$$

$D_{\text {eff }}$ can be calculated from the plot of $\ln (M R)$ versus t. Since the plot is a straight line, the slope (k) and $D_{\text {eff }}$ can be calculated by Eq. (9):

$$
k=\frac{\pi^{2} D_{e f f}}{r^{2}}
$$

where, $k$ is the constant rate of diffusion $(1 / \mathrm{s})$.

\section{Estimation of activation energy}

Temperature is not directly measurable quantity in the infrared power during drying process in this study. For the calculation of activation energy, modified form of Arrhenius equation shows the relationship between the effective diffusivity and the infrared power to sample weight [16].

$$
D_{\text {eff }}=D_{o} \exp \left(\frac{E_{a} m}{p}\right)
$$

where $D_{0}$ is the pre-exponential factor of Arrhenius equation $\left(\mathrm{m}^{2} / \mathrm{s}\right), E_{a}$ is the activation energy $(\mathrm{W} / \mathrm{kg}), p$ is the infrared power $(\mathrm{W})$, and $\mathrm{m}$ is the sample weight $(\mathrm{kg})$.

\section{RESULTS AND DISCUSSION}

\section{Analysis of drying curves}

The effects of infrared power on moisture content correspond to drying time are shown in Figure 1. According to the results in Figure 2, the infrared power had a significant effect on the moisture content of the black mulberry as expected. The results showed that drying time decreased greatly when the infrared power increased. The drying time required to reach the final moisture content of samples were 480, 375, 285, 225 and 195 min at the infrared power levels of $50,62,74,88$, and $104 \mathrm{~W}$, respectively. The average drying time decreased 2.46 times as infrared power increased from $50 \mathrm{~W}$ to $104 \mathrm{~W}$. Similar findings were also reported by several authors for various agricultural products under infrared drying [5, 22-24].

During drying, the drying rates were higher in the beginning of the process, and after that decreased with decrease of moisture content in the samples. The reason for reduction of drying rate might due to reduction in porosity of samples due to shrinkage with advancement, which increased the resistance to movement of water leading to further fall in drying rates [25]. Examination of Figure 2 that the constant drying rate period was not observed in any cases. The drying of black mulberry occurs in the falling drying rate period. These results are in good agreement as compared to the earlier studies of various vegetables [2, 12, 26].

The drying rate curves of in black mulberry are shown in Figure 3. It is clear that the drying rate decrease continuously with moisture content.

\section{Evaluation of Models}

The moisture content data obtained from the drying experiments were fitted five drying models identified in Table 1. The best model selected based on the highest $R^{2}$ and the lowest $\chi^{2}$ and RMSE values. Results of the statistical computing are shown in Table 2. The $R^{2}$ values for all models were above 0.99. 
Among the five drying models tested, Parabolic model obtained the highest $R^{2}$ values and the lowest $\chi^{2}$ and $R M S E$ values in all the infrared drying conditions studied. It is clear that, the $R^{2}, \chi^{2}$ and $R M S E$ values of this model were changed between 0.997849-0.999664, 0.000070-0.000294 and 0.007884-0.015195, respectively.

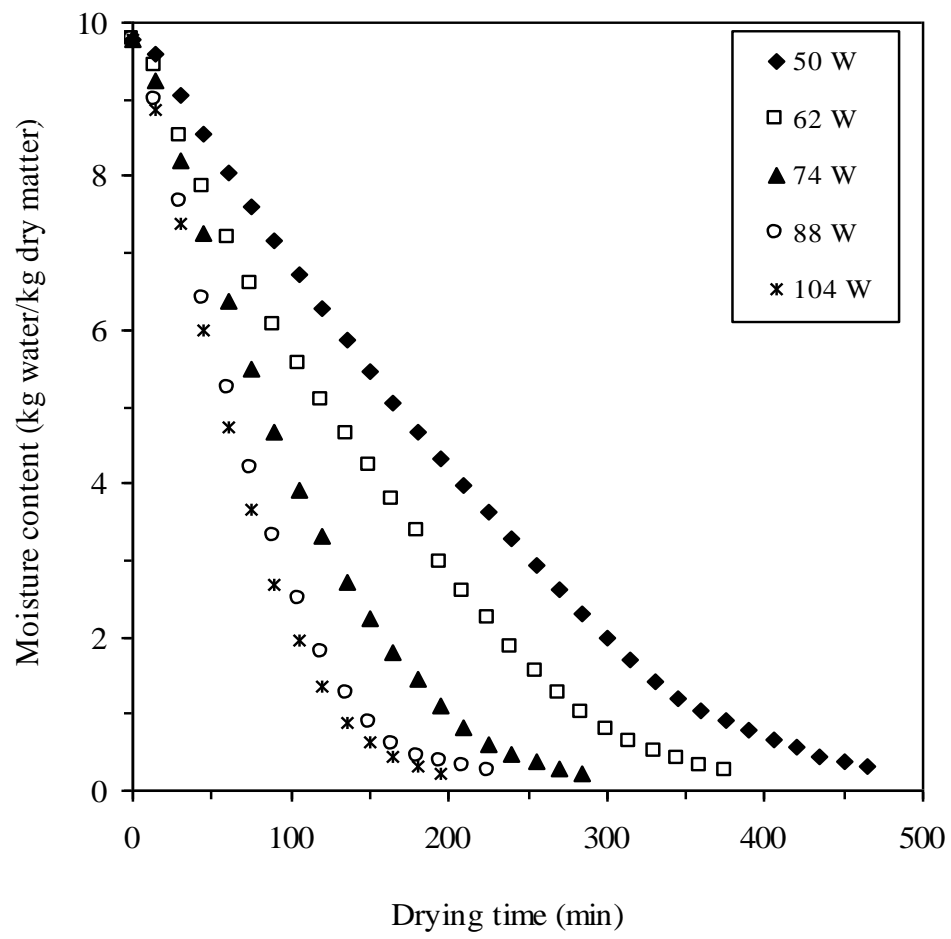

Figure 2. Moisture content during drying time at different infrared powers.

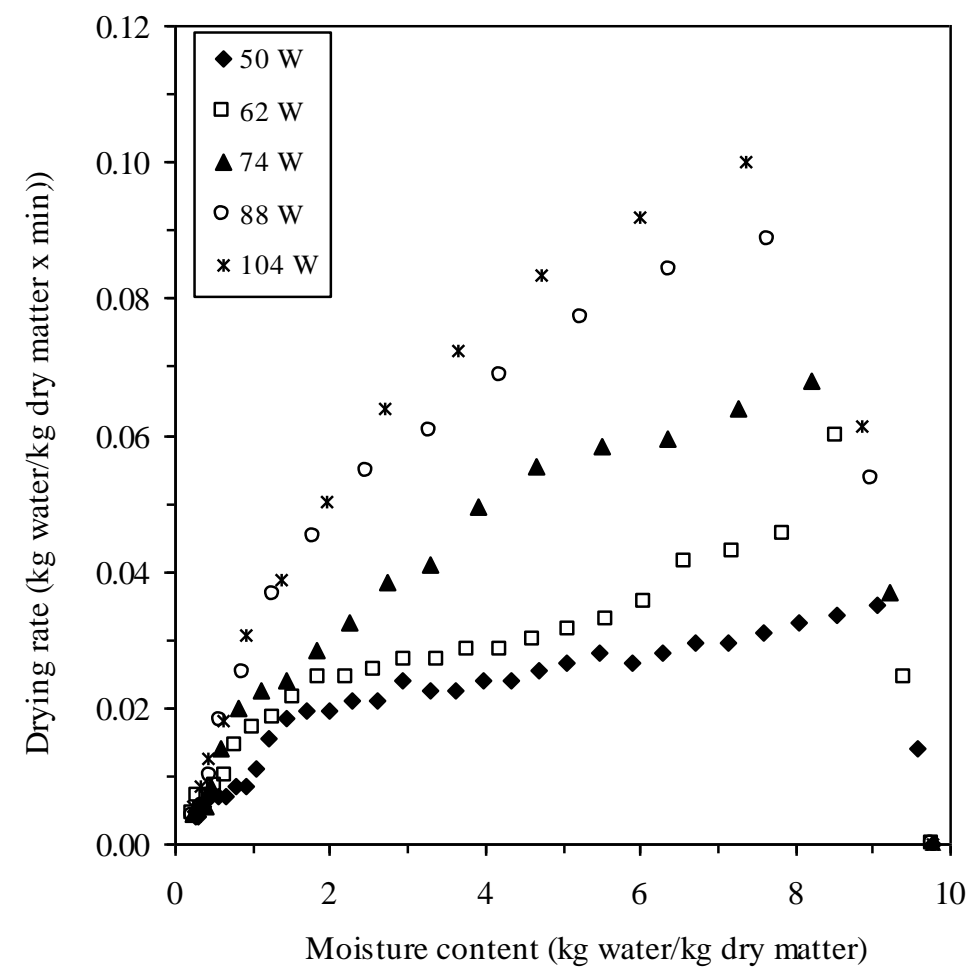

Figure 3. Drying rate as a function of moisture content at different infrared powers. 
Journal of Thermal Engineering, Research Article, Vol. 5, No. 2, Special Issue 9, pp. 13-21, February, 2019

Table 2. Estimated values of coefficients and statistical analyses obtained from various drying models for drying of black mulberry at different infrared powers

\begin{tabular}{|c|c|c|c|c|c|c|}
\hline Model & Power (W) & 50 & 62 & 74 & 88 & 104 \\
\hline \multirow{5}{*}{ Aghbashlo et al. } & $\mathrm{k}_{1}$ & 0.003083 & 0.004442 & 0.006482 & 0.008385 & 0.009409 \\
\hline & $\mathrm{k}_{2}$ & -0.001366 & -0.001495 & -0.002172 & -0.003187 & -0.003474 \\
\hline & $\mathrm{R}^{2}$ & 0.999344 & 0.999177 & 0.997951 & 0.996896 & 0.996979 \\
\hline & $\chi^{2}$ & 0.000067 & 0.000082 & 0.000229 & 0.000377 & 0.000378 \\
\hline & RMSE & 0.007958 & 0.008721 & 0.014366 & 0.018155 & 0.018007 \\
\hline \multirow{5}{*}{ Page } & $\mathrm{k}$ & 0.000454 & 0.001228 & 0.001529 & 0.001847 & 0.002185 \\
\hline & $\mathrm{n}$ & 1.432546 & 1.317380 & 1.375515 & 1.423578 & 1.419992 \\
\hline & $\mathrm{R}^{2}$ & 0.996874 & 0.995380 & 0.999656 & 0.999594 & 0.999843 \\
\hline & $\chi^{2}$ & 0.000321 & 0.000463 & 0.000038 & 0.000049 & 0.000020 \\
\hline & RMSE & 0.017368 & 0.020665 & 0.005883 & 0.006562 & 0.004109 \\
\hline \multirow{6}{*}{ Parabolic } & $\mathrm{a}$ & 1.033574 & 1.008817 & 1.032892 & 1.038542 & 1.036759 \\
\hline & $\mathrm{b}$ & -0.003734 & -0.004751 & -0.007349 & -0.009947 & -0.011038 \\
\hline & $\mathrm{c}$ & 0.000003 & 0.000006 & 0.000013 & 0.000024 & 0.000030 \\
\hline & $\mathrm{R}^{2}$ & 0.998760 & 0.999664 & 0.998899 & 0.997982 & 0.997849 \\
\hline & $\chi^{2}$ & 0.000132 & 0.000070 & 0.000130 & 0.000264 & 0.000294 \\
\hline & RMSE & 0.010941 & 0.007884 & 0.010529 & 0.014638 & 0.015195 \\
\hline \multirow{5}{*}{ Wang\& Singh } & $\mathrm{a}$ & -0.003459 & -0.004659 & -0.006899 & -0.009285 & -0.010314 \\
\hline & $\mathrm{b}$ & 0.000003 & 0.000005 & 0.000012 & 0.000022 & 0.000027 \\
\hline & $\mathrm{R}^{2}$ & 0.997298 & 0.999219 & 0.997450 & 0.996006 & 0.996011 \\
\hline & $\chi^{2}$ & 0.000278 & 0.000078 & 0.000285 & 0.000485 & 0.000500 \\
\hline & RMSE & 0.016148 & 0.008496 & 0.016024 & 0.020595 & 0.020692 \\
\hline \multirow{5}{*}{ Weibull } & $\mathrm{b}$ & 215.4467 & 162.0534 & 111.4123 & 83.19781 & 74.75629 \\
\hline & $\mathrm{a}$ & 1.4325 & 1.3174 & 1.3755 & 1.42358 & 1.41999 \\
\hline & $\mathrm{R}^{2}$ & 0.996875 & 0.995380 & 0.999656 & 0.999594 & 0.999843 \\
\hline & $\chi^{2}$ & 0.000321 & 0.000463 & 0.000038 & 0.000488 & 0.000020 \\
\hline & RMSE & 0.017368 & 0.020665 & 0.005883 & 0.020665 & 0.004109 \\
\hline
\end{tabular}

\section{Effective Moisture Diffusivity}

In Figure 4 by using experimental data, the logarithm of moisture ratio $(M R)$ is plotted versus drying time for different infrared powers. The values of effective diffusivity $\left(D_{\text {eff }}\right)$ were calculated using Eq. (9) and are shown in Figure 3. The $D_{\text {eff }}$ values of black mulberry in the infrared drying at $50-104 \mathrm{~W}$ varied between $1.14 \times 10^{-9} \mathrm{~m}^{2} / \mathrm{s}$ and $3.08 \times 10^{-9} \mathrm{~m}^{2} / \mathrm{s}$. It can be seen that $D_{\text {eff }}$ values increased greatly with increasing infrared power. Drying at 104 W has the highest value of $D_{\text {eff }}$ and the lowest value was obtained for $50 \mathrm{~W}$. The values of $D_{\text {eff }}$ from this study lie within in general range $10^{-12}$ to $10^{-8} \mathrm{~m}^{2} / \mathrm{s}$ for drying of food materials [25]. This result is similar to the results for 
hot-air drying of white mulberry [2], solar drying of white mulberry [12, 27], and microwave drying of white mulberry $[28,29]$. The effect of infrared power on effective diffusivity is defined by the following equation:

$$
D_{\text {eff }}=5 \times 10^{-10} p-6 \times 10^{-10} \quad\left(R^{2}=0.9864\right)
$$

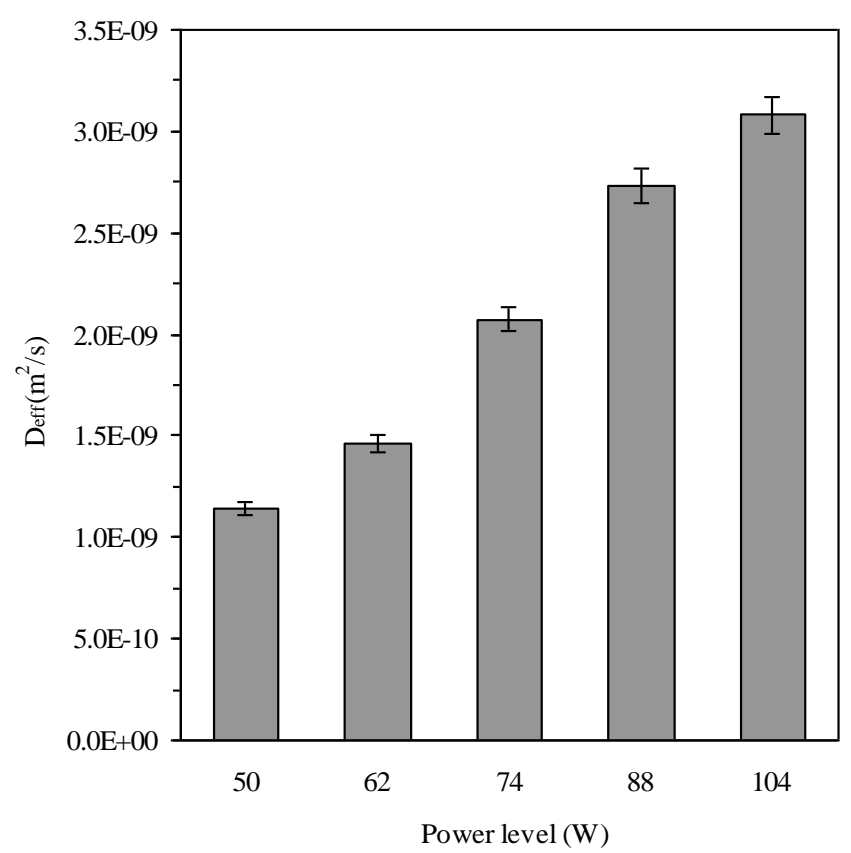

Figure 4. Variation of effective moisture diffusivity with infrared powers.

\section{Activation Energy}

The activation energy can be determined from the slope of Arrhenius plot, $\ln \left(D_{\text {eff }}\right)$ versus $m / p$ (Eq. (10)). The $\ln \left(D_{\text {eff }}\right)$ as a function of the sample weight/infrared power was plotted in Figure 5. The slope of the line is ($\left.E_{a}\right)$ and the intercept equals to $\ln \left(D_{0}\right)$. The results show a linear relationship due to Arrhenius type dependence.

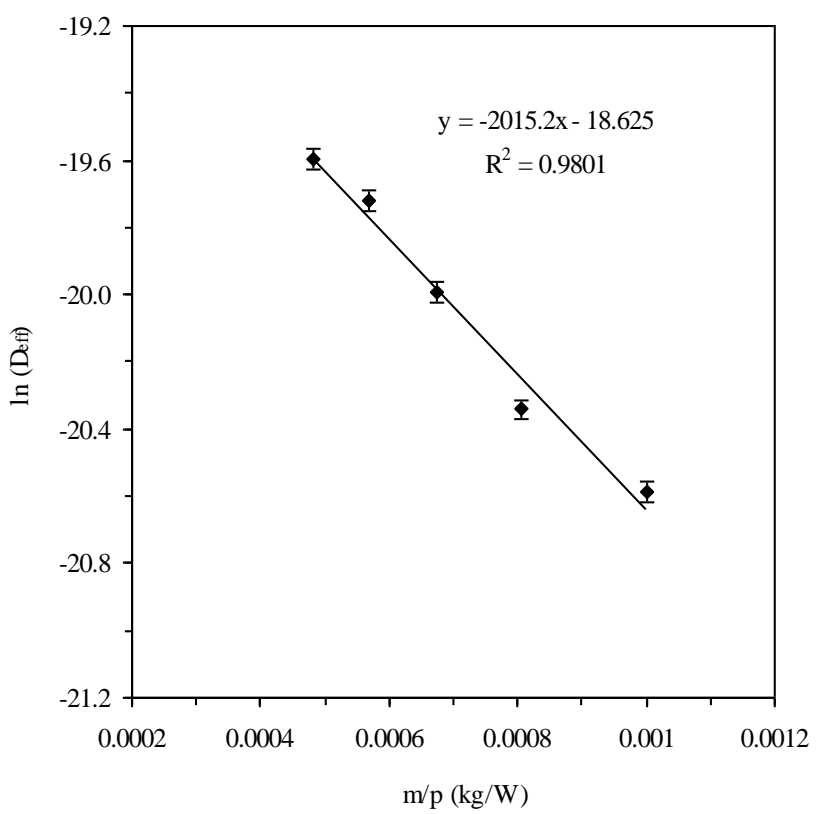

Figure 5. Arrhenius-type relationship between effective moisture diffusivity and infrared powers. 
coefficients:

Eq. (12) shows the effect of sample weight/infrared power on $D_{\text {eff }}$ of samples with the following

$$
D_{e f f}=8.152 \times 10^{-9} \exp \left(-\frac{2015.1 \mathrm{~m}}{p}\right) \quad\left(R^{2}=0.9801\right)
$$

The estimated values of $D_{0}$ and $E_{a}$ from modified Arrhenius type exponential Eq. (12) are $8.152 \times 10^{-9} \mathrm{~m}^{2} / \mathrm{s}$ and $2.015 \mathrm{~kW} / \mathrm{kg}$, respectively.

\section{CONCLUSION}

Black mulberry drying behavior was investigated in a laboratory infrared dryer. Infrared power was important factor in drying time. Drying time decreased considerably with increased infrared power. Five different mathematical models were evaluated for moisture ratios using nonlinear regression analysis. The Parabolic model gave the best representations of drying data under all experimental conditions. The effective moisture diffusivity at each infrared power was determined by Fick's second law of diffusion. An increase in the power level led to increase in the effective moisture diffusivity between $1.14 \times 10^{-9}$ and $3.08 \times 10^{-9} \mathrm{~m}^{2} / \mathrm{s}$. The dependence of effective moisture diffusivity on infrared power was expressed by a modified Arrhenius type equation. Activation energy was estimated by a modified Arrhenius type equation as $2.015 \mathrm{~kW} / \mathrm{kg}$.

\section{REFERENCES}

[1] Doymaz, İ., Kipcak, A. S., Piskin, S. (2015). Microwave drying of green bean (Phaseolus vulgaris) slices: drying kinetics and physical quality. Czech Journal of Food Sciences, 33(4), 367-376.

[2] Nowak, D., Lewicki, P. P. (2004). Infrared drying of apple slices. Innovative Food Science and Emerging Technologies, 5, 353-360.

[3] Togrul, H. (2005). Simple modeling of infrared drying of fresh apple slices. Journal of Food Engineering, 71(3), 311-323.

[4] Wang, J., Sheng, K. (2006). Far-infrared and microwave drying of peach. LWT-Food Science and Technology, 39, 247-255.

[5] Celma, A. R., López-Rodríguez, F., Blázquez, F. C. (2009). Experimental modelling of infrared drying of industrial grape by-products. Food and Bioproducts Processing, 87(4), 247-253.

[6] Caglar, A., Togrul, I. T., Togrul, H. (2009). Moisture and thermal diffusivity of seedless grape under infrared drying. Food and Bioproducts Processing, 87(4), 292-300.

[7] Akpinar, E. K. (2008). Mathematical modelling and experimental investigation on sun and solar drying of white mulberry. Journal of Mechanical Science and Technology, 22, 1544-1553.

[8] Aghbashlo, M., Kianmehr, M. H., Khani, S., Ghasemi, M. (2009). Mathematical modeling of thin-layer drying of carrot. International Agrophysics, 23, 313-317.

[9] Guan, Z., Wang, X., Li, M., Jiang, X. (2013). Mathematical modeling on hot air drying of thin layer fresh Tilapia fillets. Polish Journal Of Food And Nutrition Sciences, 63, 25-34.

[10] Wang, C. Y., Singh, R. P. (1978). A single layer drying equation for rough rice. ASAE, Paper, No: 3001.

[11] Kipcak, A. S. (2017). Microwave drying kinetics of mussels (Mytilus edulis). Research on Chemical Intermediates, 43, 1429-1445.

[12] Balbay, A., Sahin, O., Ulker, H. (2013). Modeling of convective drying kinetics of pistachio kernels in a fixed bed drying system. Thermal Science, 17, 839-846.

[13] Chayjan, R. A.,Salari, K., Abedi, Q., Sabziparvar, A. A. (2013). Modeling moisture diffusivity, activation energy and specific energy consumption of squash seeds in a semi fluidized and fluidized bed drying, Journal of Food Science and Technology, 50, 667-677.

[14] Toujani, M., Hassini, L., Azzouz, S., Belghith, A. (2013). Experimental study and mathematical modeling of silverside fish convective drying. Journal of Food Processing and Preservation, 37, 930-938.

[15] Liu, X., Qiu, Z., Wang, L., Cheng, Y., Qu, H., Chen, Y. (2009). Mathematical modeling for thin layer vacuum belt drying of Panaxnotoginseng extract. Energy Conversion and Management, 50, 928-932.

[16] Crank, J. (1975). The Mathematics of Diffusion, Oxford University Press, London.

[17] Doymaz, I. (2014). Experimental study and mathematical modeling of thin-layer infrared drying of watermelon seeds. Journal of Food Processing and Preservation, 38, 1377-1384.

[18] Ponkham, K., Meeso, N., Soponronnarit, S., Siriamornpun, S. (2012). Modeling of combined far-infrared radiation and air drying of a ring shaped-pineapple with/without shrinkage. Food and Bioproducts Processing, $90,155-164$. 
[19] Aidani, E., Hadadkhodaparast, M., Kashaninejad, M. (2017). Experimental and modeling investigation of mass transfer during combined infrared-vacuum drying of Hayward kiwifruits. Food Science and Nutrition, 5, 596-601.

[20] Singh, B., Panesar, P. S., Nanda, V. (2006). Utilization of carrot pomace for the preparation of a value added product. World Journal of Dairy \& Food Sciences, 1, 22-27.

[21] Zogzas, N. P., Maroulis, Z. B., Marinos-Kouris, D. (1996). Moisture diffusivity data compilation in foodstuffs. Drying Technology, 14, 2225-2253.

[22] Evin, D. (2011). Microwave drying and moisture diffusivity of white mulberry: Experimental and mathematical modeling. Journal of Mechanical Science and Technology, 25, 2711-2718.

[23] Akbulut, A., Durmus, A. (2009). Thin layer solar drying and mathematical modeling of mulberry. International Journal of Energy Research, 3, 687-695.

[24] Darvishi, H., Zarein, M., Minaei, S., Khafajah, H. (2014). Exergy and Energy analysis, drying kinetics and mathematical modeling of white mulberry drying process. International Journal of Food Engineering, 10(2), 269-280. 